$\mathbb{T}$ periodica polytechnica

Chemical Engineering

$51 / 2$ (2007) 3

doi: $10.3311 / p p . c h .2007-2.01$

web: http://www.pp.bme.hu/ch

(c) Periodica Polytechnica 2007

RESEARCH ARTICLE

\section{Solar energy storage by a two grade phase change material}

\author{
Gábor Bajnóczy / Edit Gagyi Pálffy / László Szolnoki / Ernő Prépostffy
}

Received 2007-01-16

\begin{abstract}
A two grade phase change material (PCM) based on $\mathrm{CaCl}_{2}-$ water system has been investigated in a PCM-water heat exchanger. The crystallization of different hydrates of $\mathrm{CaCl}_{2}$ extended the temperature range of heat storage and the storage stability was achieved by the application of wood chips as thickening agent. A short section of the heat exchanger tube (a few $\mathrm{cm}$ ) can be characterized by a maximum curve of heat transfer coefficient in function of cooling time. Longer sections (a few meter) showed nearly constant heat transfer coefficient in the range of $115+/-25 \mathrm{~W} / \mathrm{m}^{2} \mathrm{~K}$. The heat storage system is to be applied to store solar energy and the stored heat is used to preheat the water input of domestic hot water supply system.
\end{abstract}

\section{Keywords}

heat storage · phase change material · solar energy · heat transfer coefficient

\section{Acknowledgement}

The authors are indebted to the Hungarian Research Fund (OTKA T-037496) for financial support.

\section{Gábor Bajnóczy}

Department of Chemical Technology, BME, H-1111, Budapest, Budafoki ut 8., Hungary

e-mail: gbajnoczy@mail.bme.hu

\section{Edit Gagyi Pálffy}

László Szolnoki

\section{Ernő Prépostffy}

Department of Chemical Technology, BME, H-1111, Budapest, Budafoki ut 8., Hungary

\section{Introduction}

The temporal difference of energy source and energy needs made necessary the development of storage systems. The abundant amount of solar energy, which is collected during the summer, could be stored in such a big storage unit that does not come up to engineering and economic requirements. Systems which equalize the temporal difference in one or two days, can be economic. In summer the energy of the heat transfer fluid arriving from the solar collector at relatively high temperature $\left(70^{\circ} \mathrm{C}-90^{\circ} \mathrm{C}\right)$ can be stored in insulated hot-water container.

Except in summer, especially in winter, the temperature of the heat transfer fluid coming from the collector is relatively low $\left(35-60{ }^{\circ} \mathrm{C}\right)$. In this period of time which means nine months a year, one way of storage is to use solid-liquid phase change materials. In comparatively small volume the phase change materials have great storage capacity in small temperature interval. Storage systems using these heat accumulator materials can store the energy from the solar collector at lower temperature level, too in winter. The stored energy can be used for pre-heating the cold incoming water, so in the households the unit which is actually produces hot-water (gas or electric boiler) is made up by the unit storing solar energy. So the traditional system integrated with solar energy storage might moderate the cost of energy consumption.

\section{Phase Change Materials as Heat Accumulators}

In practice several phase change material (PCM) is known, such as: paraffins, fatty-acids, organic and inorganic salt hydrates, organic and inorganic eutectic compounds. [1] Theoretically isotherm heat storage in accordance with phase change temperature can be achieved by these materials.

Conditions of using phase change materials: relatively high latent heat, high heat conductivity (more than $0.5 \mathrm{~W} / \mathrm{m}^{\circ} \mathrm{C}$ ), melting temperature should be in the functional interval $\left(15^{\circ} \mathrm{C}<\mathrm{T}<90^{\circ} \mathrm{C}\right)$ if it stores solar energy), congruent melting, minimal supercooling, chemical stability, economic efficiency and aspects of environmental protection. [2,-4].

The study of heat exchange is especially important if PCM is involved in the process [5,6]. If the energy transfer medium 
is liquid the energy input is simpler and relatively high rate of heat transfer can be achieved due to the liquid - liquid heat flow [7]. The solid phase change material melts very quickly in the vicinity of heat transfer tubes and the low heat conductivity of the solid phase does not mean a barrier against the heat flow [8]. This is no longer the case of heat output. Heat extraction at the phase change temperature causes solidification on the heat exchange surface. The more heat extracted thicker layer formed. The heat flow is controlled by heat conductivity of the continuously thickening layer. The mathematical description of this process is easier in case of organic phase change materials (paraffins, stearic and palmitic acid [9]) because the solid layer on heat exchange surface increases smoothly. Inorganic salt hydrates such as $\mathrm{CaCl}_{2} \cdot 6 \mathrm{H}_{2} \mathrm{O}$ may form small or large individually growing crystals in the function of heat extraction rate. Due to rough surface the value of heat transfer coefficient (U) is practically measured experimentally.

In the course of the experiments a special phase change material was examined that stored heat in two different temperature grades [10]. The grade which stores heat on lower temperature is isotherm $\left(29^{\circ} \mathrm{C}\right)$. The other links to higher temperature grade $\left(29-42{ }^{\circ} \mathrm{C}\right)$, that can be considered a storage system with high apparent specific heat. The reason for the high apparent specific heat is the continuous crystallization of the PCM, during the temperature drop and energy production in the interval mentioned above.

\section{Heat Storage by two Grade Phase Change Material}

The two grade phase change material, examined in a preheater, that can be linked to the domestic hot-water system is a solution containing $211.4 \mathrm{~mol}$ of $\mathrm{CaCl}_{2} / 1000 \mathrm{~mol} \mathrm{H}_{2} \mathrm{O}$. The way of heat storage process is shown on the phase diagram of $\mathrm{CaCl}_{2}-\mathrm{H}_{2} \mathrm{O}$ (Fig. 11).

The two grades can be connected to two peritectic points $P_{1}$ (211.4 mol $\left.\mathrm{CaCl}_{2} / 1000 \mathrm{~mol} \mathrm{H}{ }_{2} \mathrm{O} ; \mathrm{mp} .43 .3^{\circ} \mathrm{C}\right)$ and $P_{2}(166,6$ mol $\mathrm{CaCl}_{2} / 1000 \mathrm{~mol} \mathrm{H}_{2} \mathrm{O}$; mp. $29.9^{\circ} \mathrm{C}$ ). If the phase change material is heated above the appropriate temperature $\left(P_{1}\right)$, the crystals melt.

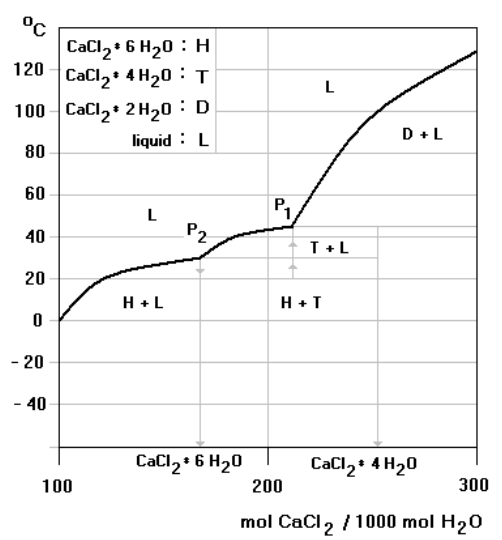

Fig. 1. Phase diagram section of the $\mathrm{CaCl}_{2}$ - water system
During the cooling the melt preserves the peritectic composition, until it reaches point $P_{1}$. From this point the crystallization of $\mathrm{CaCl}_{2} \cdot 4 \mathrm{H}_{2} \mathrm{O}$ starts which causes the release of crystallization heat and goes on until the temperature reaches the temperature of point $P_{2}$. During the phase change the temperature follows the liquidus line as a function of the amount of solidified $\mathrm{CaCl}_{2} \cdot 4 \mathrm{H}_{2} \mathrm{O}$ and gradually decreases to $29.9^{\circ} \mathrm{C}$. The process is considered to be the first grade of the heat storage and the system behaves as a storage medium with great virtual specific heat value. Continuing the heat extraction in the presence of seeding crystals $\left(\mathrm{SrCl}_{2} \cdot 6 \mathrm{H}_{2} \mathrm{O}\right.$ and $\left.\mathrm{Sr}(\mathrm{OH})_{2} .8 \mathrm{H}_{2} \mathrm{O}\right)$ the rest of melt solidifies as $\mathrm{CaCl}_{2} \cdot 6 \mathrm{H}_{2} \mathrm{O}$. Theoretically this process - the second grade - is isotherm.

During the energy storage period the starting point $\mathrm{P}_{2}$, where $\mathrm{CaCl}_{2} .6 \mathrm{H}_{2} \mathrm{O}$ starts melting in the presence of solid $\mathrm{CaCl}_{2} .4$ $\mathrm{H}_{2} \mathrm{O} . \mathrm{CaCl}_{2} .6 \mathrm{H}_{2} \mathrm{O}$ melts totally at $29.9{ }^{\circ} \mathrm{C}$ (semicongruent melting). Increasing the temperature, the liquid dissolves more and more $\mathrm{CaCl}_{2} .4 \mathrm{H}_{2} \mathrm{O}$ (endothermal process). The rate of dissolution is generally not high enough to reach the equilibrium, therefore when the temperature exceeds $43.3{ }^{\circ} \mathrm{C}, \mathrm{CaCl}_{2} .4 \mathrm{H}_{2} \mathrm{O}$ melts. The melting process is peritectic, and a small amount of solid $\mathrm{CaCl}_{2} .2 \mathrm{H}_{2} \mathrm{O}$ will be formed during the melting. The precipitated and settled material should be dissolved in the liquid phase otherwise loss of heat storage capacity can be measured in the function of storage cycles.

The storage capacities of the two grade PCM and the relevant processes are summarized in Table 1 .

Tab. 1. Theoretical storage capacity of the two grade phase change material

\begin{tabular}{|c|c|c|c|c|}
\hline \multirow[t]{2}{*}{ Grade } & \multirow{2}{*}{$\begin{array}{l}\text { Temperature } \\
\text { interval of } \\
\text { accumulation }\end{array}$} & \multirow{2}{*}{$\begin{array}{c}\text { Theoretical } \\
\text { storage } \\
\text { capacity } \\
{\left[\mathrm{kJ} / \mathrm{dm}^{3}\right]}\end{array}$} & \multicolumn{2}{|c|}{$\begin{array}{l}\text { Process responsible for heat } \\
\text { accumulation }\end{array}$} \\
\hline & & & charge & Exhaust \\
\hline I. & $60^{\circ} \mathrm{C}-30^{\circ} \mathrm{C}$ & 175 & $\begin{array}{l}\text { melt of } \\
\mathrm{CaCl}_{2} \cdot 4 \mathrm{H}_{2} \mathrm{O} \\
\text { dissolution } \\
\mathrm{CaCl}_{2} \cdot 2 \mathrm{H}_{2} \mathrm{O}\end{array}$ & $\begin{array}{l}\text { crystallization of } \\
\mathrm{CaCl}_{2} .4 \mathrm{H}_{2} \mathrm{O} \\
\text { of }\end{array}$ \\
\hline II. & $30^{\circ} \mathrm{C}-12^{\circ} \mathrm{C}$ & 199 & $\begin{array}{l}\text { melt of } \\
\mathrm{CaCl}_{2} \cdot 6 \mathrm{H}_{2} \mathrm{O}\end{array}$ & $\begin{array}{l}\text { crystallization of } \\
\mathrm{CaCl}_{2} .6 \mathrm{H}_{2} \mathrm{O}\end{array}$ \\
\hline$I+I \mid$ & $60^{\circ} \mathrm{C}-12^{\circ} \mathrm{C}$ & 374 & & \\
\hline
\end{tabular}

\section{The Heat Exchanger Charged with Two Grade Phase Change Material}

The preliminary experiments were performed in a small horizontal tube in tube heat exchanger where the phase change material was placed in closed copper tube (diameter: $2.55 \mathrm{~mm}$, length:350 $\mathrm{mm}$ ). The composition of the storage material: $211.4 \mathrm{~mol} \mathrm{CaCl}_{2} / 1000 \mathrm{~mol} \mathrm{H}_{2} \mathrm{O}$ and 0,3 mass \% $\mathrm{Sr}(\mathrm{OH})_{2} .8$ $\mathrm{H}_{2} \mathrm{O}$ crystals were applied as seeding crystals. The effect of phase separation due to peritectic melting was reduced by wood chips in the storage materials. The high surface loose structure 
Fig. 2. Exhaust curves of two grade phase chan materials containing different additives A: seeding crystals, B: wood chips, $\mathrm{C}$ : seeding cry tals $\left(0,3\right.$ mass $\left.\% \mathrm{Sr}(\mathrm{OH})_{2} .8 \mathrm{H}_{2} \mathrm{O}\right)$ and wood chip Cooling water: $12{ }^{\circ} \mathrm{C}$, flow rate: $0,1 \mathrm{dm}^{3} / \mathrm{min}$. Cyc number:30.
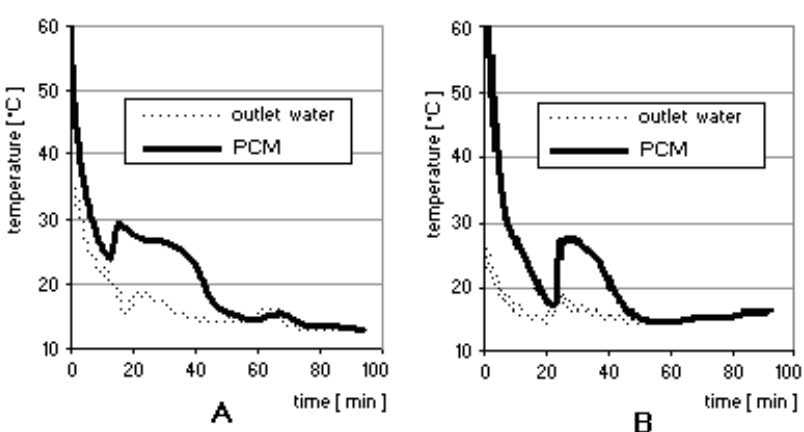

of the additive keeps solid crystals of calcium chloride dihydrate from the aggregation on the bottom of the tubes. The temperature of the phase change material in the middle of the tube and the inlet and outlet temperature of the heat transfer medium (water) were registered during the repeated cycles.

The thermal properties of the two grade PCM was measured in a proper sized pilot heat exchanger, too (Table 2). Horizontal layers of copper tube coil was immersed into the phase change material containing wood chips $(\sim 10$ mass $\%)$. The heat transfer fluid flowed in the copper tube.

The hot water coming from the sun collector was simulated by a flow through $21 \mathrm{~kW}$ electric boiler, which can be adjusted between $40^{\circ} \mathrm{C}-60^{\circ} \mathrm{C}$ transformation range. The cooling water was gained from the tap introduced into a thermostat to keep the temperature constant. Effluent and influent heat transfer fluid temperature was recorded by thermometers connected to computer. In the middle of the heat exchanger box a thermometer was placed to measure the temperature of the phase change material.

\section{Results}

5.1 Preliminary Experiments in the Tube in Tube Heat Exchanger

Tree storage tubes have been examined in the preliminary experiment. The composition of the PCM was the same (211.4 mol $\mathrm{CaCl}_{2} / 1000 \mathrm{~mol} \mathrm{H}_{2} \mathrm{O}$ ), but different additives (only seeding crystals of $\mathrm{Sr}(\mathrm{OH})_{2} .8 \mathrm{H}_{2} \mathrm{O}$, wood chips alone, seeding crystals and wood chips) were applied (Fig. 2). The exhaust curves have been measured after the 30th cycle when the heat storage capacity became nearly constant.

The PCM containing only seeding crystals (Fig. 2A.) shows reliable phase change with low supercooling, but the repeating temperature peaks on the PCM temperature curve suggest the formation of different crystal phases. Solid - solid transformation can also be detected after the 60. min cooling time. The high surface of wood chips serves sites for the nucleation of liquid - solid phase transformation, but the degree of supercooling without seeding crystals seems to be high (Fig. 2B). The terminal increase of the PCM temperature curve makes the solid solid transformation likely. The best results have been achieved by the common application of seeding crystals and wood chips (Fig. 2C). The phase change is accompanied by low supercool- ing and the PCM temperature remains nearly constant during the crystallization of $\mathrm{CaCl}_{2} \cdot 6 \mathrm{H}_{2} \mathrm{O}$. The freezing point deviation of $\mathrm{CaCl}_{2} .6 \mathrm{H}_{2} \mathrm{O}\left(30{ }^{\circ} \mathrm{C}\right)$ was due to the technical grade of the PCM applied. The initial temperature of the outlet cooling water is much higher in case of the lack of wood chips due to the reduced heat flow caused by the chips.

The heat transfer coefficient shows an interesting curve during the crystallization of the two grade phase change material containing wood chips and seeding crystals (Fig. 3).

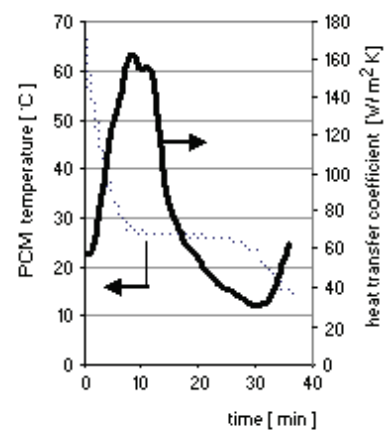

A

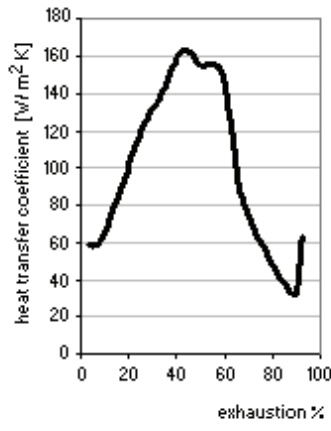

$\mathrm{B}$
Fig. 3. Change of heat transfer coefficient and PCM temperature in function of cooling time (A) and exhaustion rate (B). Additives: $\left(0,3\right.$ mass $\% \mathrm{Sr}(\mathrm{OH})_{2} .8$ $\mathrm{H}_{2} \mathrm{O}$ ) and wood chips.

The heat transfer coefficient shows an increase during the exhaust of the first grade that is due to the crystallization as heat source close to the wall. The increasing amount of solid crystals on the wall exerts a growing insulation effect and the heat transfer coefficient decreases (Fig. 34). In function of exhaustion percentage the first grade can be characterized by an increasing and the second grade by a decreasing heat transfer coefficient. Close to the end of the exhausting process the value of heat transfer coefficient starts increasing again. Presumably exothermal solid - solid phase change processes of non-stable phases cause the increase.

During the first section of the melting process the heat transfer coefficient decreases (Fig. 4). The sink of heat, the surface of melting phase is drawing off the inner surface of the tube and the melted liquid insulation layer is getting more and thicker. Due to the wood chips there is no effective convection heat transfer. In the lack thickening additives in the phase change material the heat transfer coefficient during the melting process is about two or four times greater than that of the cooling process. The main 
Tab. 2. Main parameters of the pilot storage system containing two grade phase change material.

\begin{tabular}{lc}
\hline Outer dimensions: & $450 \times 450 \times 515 \mathrm{~mm}$ \\
\hline Wall : & $2 \mathrm{~mm}$ steel plate \\
\hline Insulation: & $15 \mathrm{~mm}$ plastic foam \\
\hline $\begin{array}{l}\text { Volume of the phase change mate- } \\
\text { rial containing wood chips }\end{array}$ & $26,5 \mathrm{dm}^{3}$ \\
\hline Surface of the copper coil & $0,2 \mathrm{~m}$ \\
\hline Length of the copper tube & $8 \mathrm{~m}$ \\
\hline Outer diameter of the copper tube & $8 \mathrm{~mm}$ \\
\hline Hot water supply & $60^{\circ} \mathrm{C}$ \\
\hline Cooling water & $12^{\circ} \mathrm{C}$ \\
\hline
\end{tabular}

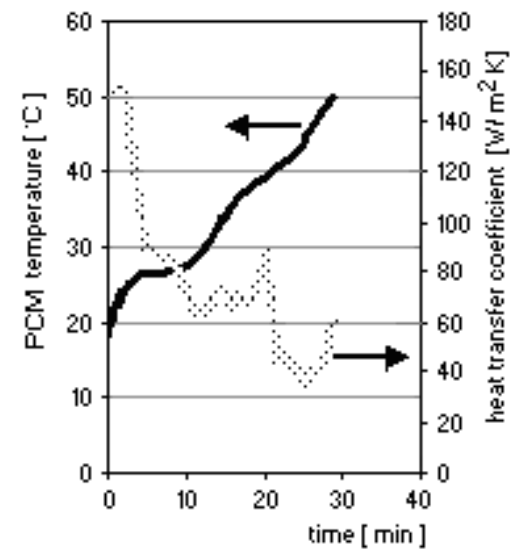

Fig. 4. Change of heat transfer coefficient and PCM temperature in function of heating process Additives: $\left(0,3\right.$ mass $\%$ r Sr$\left.(\mathrm{OH})_{2} .8 \mathrm{H}_{2} \mathrm{O}\right)$ and wood chips

advantage of the thickener is to reduce the storage decrease of the phase change materials during the cycle numbers.

\subsection{Pilot Heat Exchanger}

The first planned pilot heat exchanger contained the phase change material in closed copper tubes and the hose bundle was inserted into a tank containing the heat transfer fluid. The large amount of copper used in the heat exchanger made the structure very expensive. To reduce the cost an inverse method has been applied, the heat transfer fluid flowed in a copper spiral immersed into the mass of two grade phase change material containing wood chips and seeding crystals. In this case a rough estimate of the heat transfer coefficient could be measured inserting a thermometer into the middle of PCM mass. The temperature difference between the PCM temperature and the logarithmic average temperature of the heat transfer fluid was applied in the approaching calculation of the heat transfer coefficient during the processes. The calculated heat transfer coefficient is valid only for the given arrangement. The variation of the temperature and heat transfer coefficient during the first cooling cycle is shown in Fig. 5. The temperature change of the two grade phase change material is very similar to the former ones. The continuously decreasing section - crystallization of

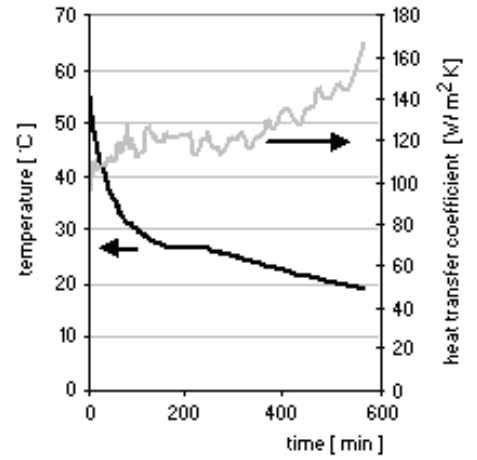

Fig. 5. Change of PCM temperature and heat transfer coefficient in the pilot heat exchanger (1. cooling cycle), flow rate $2,4 \mathrm{dm}^{3} / \mathrm{min}$

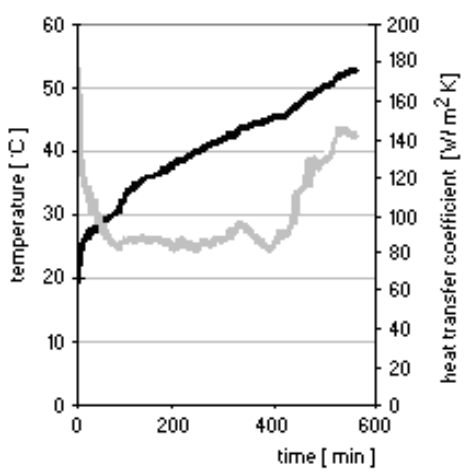

Fig. 6. Change of PCM temperature and heat transfer coefficient in the pilot heat exchanger (1. heating cycle), flow rate $2,4 \mathrm{dm}^{3} / \mathrm{min}$

$\mathrm{CaCl}_{2} .4 \mathrm{H}_{2} \mathrm{O}$ - is followed by an isotherm one (crystallization of $\mathrm{CaCl}_{2} \cdot 6 \mathrm{H}_{2} \mathrm{O}$ ). After the isotherm section a continuous drop can be seen due to the insulation layer around the thermometer.

The shape of the heat transfer curve has been changed if the PCM is placed around the heat transfer coil. From the point of heat exchanger design the nearly constant heat transfer coefficient was advantageous. Constant heat transfer coefficient characterized the larger section of heating period, too (Fig. 6). Increasing the cycle number the constant character of the heat transfer coefficient has remained, but a slow degradation of the PCM can be seen, because the isotherm section of the PCM dur- 


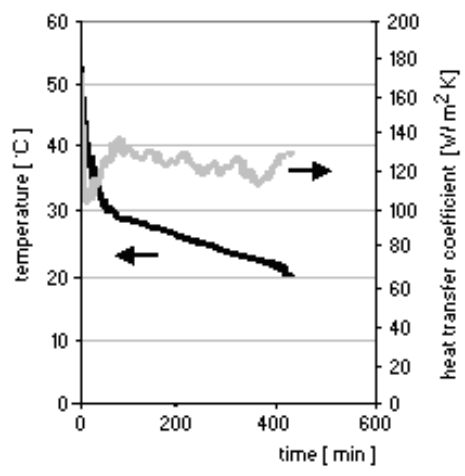

Fig. 7. Change of PCM temperature and heat transfer coefficient in the pilot heat exchanger (100. cooling cycle), flow rate $2,4 \mathrm{dm}^{3} / \mathrm{min}$

ing the cooling period has been shortened after the 100 . cycle (Fig. 77.

The constant character of the heat transfer coefficient might be due to the long heat transfer coil. The layers formed near the heat transfer surface during cooling are independent of the fact that the PCM can be found inside or outside the tube. In case of short tube the heat transfer coefficient shows maximum value in the function of time (Fig. 3). Along the long tube the surface closer to the cooling water input is characterized by the regressive heat transfer coefficient (quick crystallization and growing insulation layer on the surface), and at the far part the heat transfer is much better because liquid phase is closer to the surface (slower crystallization). The two adverse affects result in a nearly constant heat transfer coefficient.

\section{Conclusions}

The $\mathrm{CaCl}_{2}$ - water system is a possible solution for the energy storage in the temperature range of $20^{\circ} \mathrm{C}-60^{\circ} \mathrm{C}$. The heat removal is accompanied by the crystallization of different crystal hydrates and the continuous phase change widens the temperature interval for heat storage. A system can be stabilized by wood chips as thickening agent and $\mathrm{Sr}(\mathrm{OH})_{2} .8 \mathrm{H}_{2} \mathrm{O}$. If the heat transfer medium is inside the tube and the phase change material is around the tube the heat transfer coefficient versus time at a short section of the tube shows a maximum curve at heat removal. Longer tube section examined showed nearly constant heat transfer coefficient making the plan of the heat exchanger easier.

\section{References}

1 Farid M M, A Review on Phase Change Energy Storage: Materials and Application, Energy Conversion and Management 45 (2004), 1597-1615.

2 Kaygusuz K, Phase Change Energy Storage for Solar Heating Systems, Energy Sources 25 (2003), 791-807.

3 Fan Y F, Zhang X X, Wang X C, Li J, Zhu Q B, Super-cooling Prevention of Microencapsulated Phase Change Material, Thermochimica Acta 413 (2004), 1-6.

4 Zalba B, Marin J M, Cabeza LF, Mehling H, Review on Thermal Energy Storage with Phase Change Materials, Heat Transfer Analysis and Applications, Applied Thermal Engineering 23 (2003), 251-283.
5 Wei J, Kawaguchi Y, Hirano S, Takeuchi H, Study on a PCM Heat Storage System for Rapid Heat Supply, Applied Thermal Engineering 25 (2005), 2903-2920.

6 Hisham E, Hisham E D, Eman A, Heat Transfer Characteristics during Melting and Solidification of Phase Change Energy Storage Process, Industrial \& Engineering Chemistry Research 43 (2004), 5350-5357.

7 Ronny H, Mahlia T M I, Masjuki H H, Thermal and Melting Heat Transfer Characteristics in a Latent Heat Storage System Using Mikro, Applied Thermal Engineering 25 (2005), 1503-1515.

8 Hisham E, Hisham E D, Amani A A, Heat transfer during phase change of paraffin wax stored in spherical shells, Journal of Solar Energy Engineering 127 (2005), 357-365.

9 Rozanna D, Chuah T G, Salmiah A, Choong S Y, Thomas M S, Fatty Acids as Phase Change Materials (PCMs) for Thermal Energy Storage, International Journal of Green Energy 1 (2004), 495-513.

10 Bajnóczy G, Gagyi Pálffy E, Prépostffy E, Zöld A, Heat Storage by two Phase Change Material, Periodica Polytechnica Chem. Eng. 43 (1999), 137147. 